\title{
Study of Tea Aroma Based on Zinc Oxide Nanorod Sensing Element
}

\author{
I.B. Karki*, J.J. Nakarmi*, P.K. Mandal** and S. Chatterjee** \\ * Central Department of Physics, Tribhuvan University, Kathmandu, Nepal \\ ** Department of Physics, University of North Bengal, Siliguri-734013, India \\ Correspondance: suman_chatterjee@hotmail.com
}

\begin{abstract}
Flavour type of tea liquor is a very important factor in identification of quality of Indian tea. Though the main aromatic ingredients in made tea are same, the quality of made tea mainly differ from their flavour types, which rely on their trace volatile components. CTC Tea is known for its strength and processed to retain its strong taste whereas Orthodox Tea is processed to retain mostly its aroma. Usually the Quality of tea is sensed by Tea Tasters and classified by smelling and very few devices are available to calibrate the Flavour. In this paper, resistance change of zinc oxide nanorods was investigated in an atmosphere of different types of tea infusion with an objective to produce a low cost alternative to classify tea by its quality. Zinc Oxide nanorods were fabricated on a glass substrate by sol-gel spin coating technique. The ZnO film possessed a columnar structure consisting of small crystals with an average grain size of around $5 \mathrm{~nm}$. The sensing properties of the $\mathrm{ZnO}$ film were tested for two different Tea liquors, namely, Assam CTC Tea and Darjeeling Orthodox Tea. An obvious change in resistance of the $\mathrm{ZnO}$ film was observed when the sensor was exposed to gas mixture. The Nanostructured elements showed higher sensitivity than the larger sized grains and pores. The response time was quite fast with large value of signal-to-noise ratio. This work shows potential application of nanostructured zinc oxide as one of the sensing elements in a sensor array for monitoring the quality of Indian tea.
\end{abstract}

Keywords: Zinc Oxide, nanorod, sensor, tea aroma.

\section{Introduction}

Tea is probably the most popular drink worldwide. Among all the beverages consumed worldwide, tea is a very popular one and used by all strata of people. There are several types of tea like black tea, green tea, Oolong tea etc., and out of these, black tea is the most common beverage. Black tea has got two major varieties, viz., [1] orthodox and [2] CTC (Cut-TearCurl operations are performed during production of this type of tea). For measurement of tea quality, unfortunately no instrumental methods are deployed on regular basis in the industry and for the assessment of Quality, traditional methods of employing professional tea tasters are still being practiced. These tasters, based on their experience and judgment, assess the quality of tea and the pricing of tea is made accordingly. The tea-tasters give a mark in the range of 1 to 10 each for leaf quality, infusion and liquor of the sample [1]. This method is purely subjective and error-prone. Thus there is a demand in the industry to have low-cost, portable solutions for quality evaluation of black tea. In this regard, electronic nose has been demonstrated to be an appropriate candidate [2] for the same.

The flavour in different commercial organic products like Tea, Coffee, Wine, etc. arises from Volatile organic compounds (VOC) emitted during infusion. VOCs are commonly used as ingredients in household products or in industrial processes where they normally get vaporized at room temperature and can be breathed, and unfortunately, many VOCs can cause adverse health effects[3]. Other synthetic products such as paints, wax or fuels can release toxic vapors when they are stored; even some foods, such as beverages, fish and meat products, emit organic vapours[4]. VOCs are also present in some workplaces, especially in the chemical industries; in these cases, it is important to monitor the concentration of the vapors to safeguard the health of the workers, and also to keep atmospheric 
emissions under control in order to avoid environmental hazards. Finally, other inorganic gases such as hydrogen or oxygen also need to be monitored because of the high risk of explosions if their concentrations surpass safe levels. Therefore sensing of VOC's has attracted increasing interest focused on their detection, monitoring and analysis.-

Porous nanostructured oxide materials like $\mathrm{ZnO}$ and $\mathrm{SnO}_{2}$ have been studied extensively primarily for detection of inorganic gases [5]. Recently, $\mathrm{ZnO}$ have been extensively studied for applications in practical gas sensing conversion devices [6,7]. $\mathrm{ZnO}$ is one of the potential semiconductor materials in sensor due to its fine physical, chemical and optical properties $[8,9,10]$. The most important aspect of the $\mathrm{ZnO}$ material is that it is completely an environment-friendly direct band gap material with wide bandgap energy of $3.37 \mathrm{eV}$ and high exciton binding energy of $\sim 60 \mathrm{meV}$. Another attractive feature of $\mathrm{ZnO}$ is that its bandgap energy can be engineered by changing dopant materials[11].

$\mathrm{ZnO}$ is an interesting chemically and thermally stable n-type semiconductor with a large exciton binding energy $(60 \mathrm{MeV})$ and large band gap $(3.37 \mathrm{eV})$ energy. $\mathrm{ZnO}$ can be grown at relatively low temperatures as compared to other wide band gap semiconductors [10]. Inexpensive substrate and low-temperature growth make these devices feasible to manufacture at a lower cost. However, these developments, in the mean time, demand a good reproducibility and clear understanding of the stability of thin film based multi-layered structures employed in the devise design [11]. $\mathrm{ZnO}$ nanomaterial also appears to be the mostly studied one as it exhibits a wide variety of nanostructures such as nanowires [4], nanowalls [5, 6], nanobelts [6], nanorods [8], nanosheets[8], and so on. Recent research has demonstrated that the creation of $\mathrm{ZnO}$ nanostructures in highly oriented and ordered arrays is of crucial important for the development of novel devices [9]. Ithas been recognized as one of the promising nanomaterials in a broad range of high technology applications, e.g., surface acoustic wave device[4], chemical sensor [5], photonic crystals [12], light emitting diodes [13], varistors[6], and photoanode films of solar cell $[7,8]$. Among its applications, $\mathrm{ZnO}$ nanowire is receiving greater interests for use in gas sensors for detecting the VOCs, for example, ethanol. $\mathrm{ZnO}$ nanowires prepared by a reactive thermal deposition method were used for ethanol sensing[9]. Very recently, nanocrystalline $\mathrm{ZnO}$ gas sensors have attracted more interest due to their better properties of detecting pollutants, toxic gases, alcohols and food freshness, especially fish freshness[14], or as gas-sensing films integrated on one chip to make an "electronic nose"[15]. The sensitivities of gas sensors can be greatly improved by doping $\mathrm{MnO}_{2}, \mathrm{TiO}_{2}$ and $\mathrm{Co}_{2} \mathrm{O}_{3}$. In some recent paper, identification of flavour components through pattern recognition analysis[16,17] of Chinese liquors was carried out using doped nano $\mathrm{ZnO}$ gas sensor array and different statistical techniques were compared for their classification ability[18].

In our study, zinc oxide nanorods based sensor has been developed and characterized. The fabricated sensor element was tested for its resistive response for evaluation of quality of two different types of tea infusion Orthodox and CTC. The performance of the sensor elements was characterized in different temperature of operation of the sensor element and different sensor characteristics were evaluated. Keeping in view of the small variation of the resistivity with changing gas environment, the response is detected through an appropriate circuit in order to improve its sensitivity. A Whetstone bridge circuit is used with compensation of cross sensitivity due to temperature variation of the sensor element.

\section{Experimental}

\section{Synthesis of $\mathrm{ZnO}$ nanorod}

Spin-coating is a simple method for preparing $\mathrm{ZnO}$ nanoseed from Zinc acetate solution. In this process, we prepared $5 \mathrm{mM}$ solution of Zinc acetate dehydrate, $\left(\mathrm{CH}_{3} \mathrm{COO}\right)_{2} \mathrm{Zn}, 2 \mathrm{H}_{2} \mathrm{O}$, (98\% Merck) with methanol. The mixture was well mixed using an ultrasonic bath for $1 \mathrm{hr}$ and then the resultant paste was dropped over a glass plate and the solution spun at $1000 \mathrm{rpm}$ for $30 \mathrm{~s}$ using a spin coater. Thus the nano layer of Zinc acetate solution is spread uniformly on a rotating substrate $[19,20]$. The coated substrates were heated to $350^{\circ} \mathrm{C}$ in conventional oven for $30 \mathrm{~min}$ to yield layers of $\mathrm{ZnO}$ islands with their (100) plane parallel to the substrate 
surface[21]. After evaporation of solvent, a thin $\mathrm{ZnO}$ film was formed whose thickness can be controlled by repeating the above process. Concentration of the solution in the spin coater and spinning rate of the substrate also play important roles in adjusting the thickness of the formed seed layer. For preparing $\mathrm{ZnO}$ nanorods standard sol-gel protocol was used[22]. $\mathrm{ZnO}$ nanoseed were spin-coated using zinc acetate solution In this process, we prepared $5 \mathrm{mM}$ solution of zinc acetate dehydrate, $\left(\mathrm{CH}_{3} \mathrm{COO}\right)_{2} \mathrm{Zn}, 2 \mathrm{H}_{2} \mathrm{O},(98 \%$ Merck) with distilled methanol. The solution was spun on clean glass substrates (with heater coil imprinted on back side) at $1000 \mathrm{rpm}$ for 30s using a Programmable Spin Coater (Apex Technologies, Model SCU-2008C). The substrates, now covered with a film of zinc acetate crystallites, were heated to $350^{\circ} \mathrm{C}$ in an oven for $30 \mathrm{~min}$ to yield layers of $\mathrm{ZnO}$. After evaporation of solvent, a thin $\mathrm{ZnO}$ film was formed.

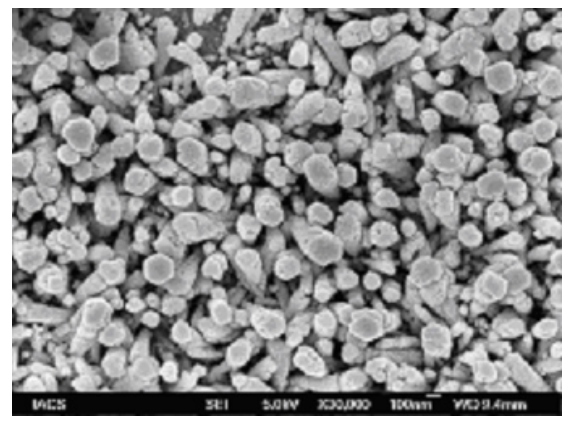

Fig.1: Scanning electron microscope (SEM) picture of $\mathrm{ZnO}$ nanorod film grown on glass plate

The formation of phases was ascertained through study of $\mathrm{x}$-ray diffraction pattern of the film calcined at various temperatures. Results showed pure $\mathrm{ZnO}$ phase formed at $350^{\circ} \mathrm{C}$ and above. For proper microstructure of sensor element $350^{\circ} \mathrm{C}$ was taken as optimum sintering temperature. The fabricate sensor material is characterized through SEM and the picture (Fig.1) shows clear $\mathrm{ZnO}$ nanorods aligned vertically perpendicular to substrate plane.

\section{Fabrication of Device structure and measurement}

Two interpenetrating comb like electrode structures were made with silver paste on the deposited film and was cured at $150^{\circ} \mathrm{C}$. Finally two electrodes were soldered with copper wires for connecting with Whetstone Bridge circuit for measurement of off-balance voltage due to resistance change of the element.

Dry tea leaves were weighed $(10 \mathrm{gms})$ and placed in a glass flask and appropriate amount $(500 \mathrm{ml})$ of water is added as shown in Fig.2. Finally the sample is heated at $100^{\circ} \mathrm{C}$ while measurement of output voltage of the circuit was arried out.

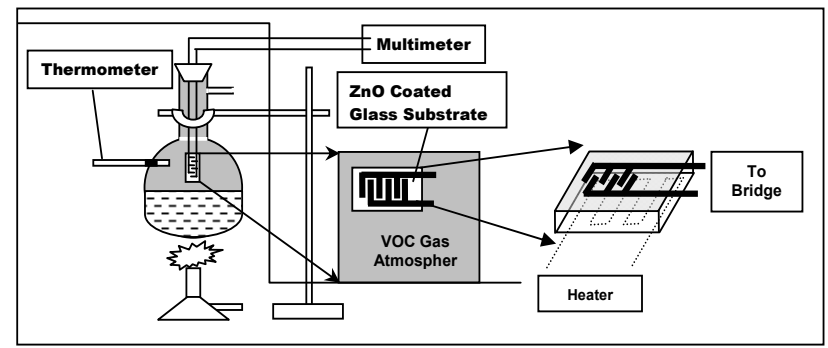

Fig.2: Schematic picture of sample measurement system in static gas environment

The output for the sensor is connected to a Whetstone bridge circuit consisting of a resistance (of same order of resistance of the sensors) a variable resistance (For bridge balancing) and two sensors, one for measurement and one for temperature compensation as shown in Fig.3. The resistances are of same order of the sensor elements while the variable resistance is adjusted for balancing of the bridge. Two exactly similar sensor elements heated simultaneously at same temperature were connected at other two arms of the bridge. One of the element being placed in the gas environment (tea infusion), while the other in open atmosphere (reference). The bridge is powered through a dc power supply (12V).

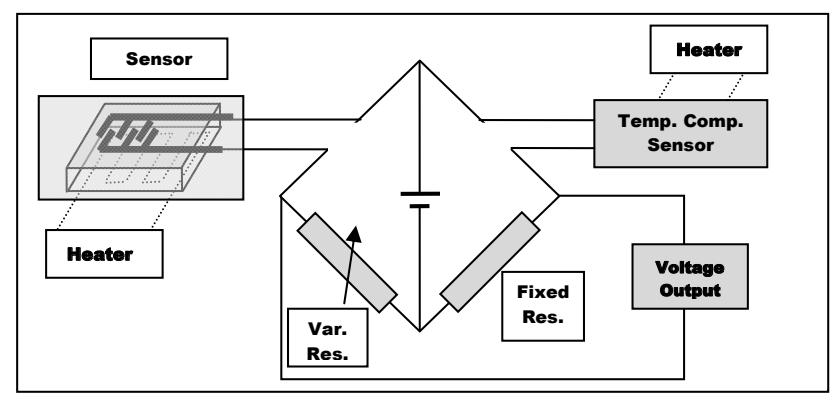

Fig.3: Schematic picture of sample measurement system in static gas environment

\section{Results and Discussion}

Response characteristics 
The response characteristics of semiconducting $\mathrm{ZnO}$ film in the Whetstone bridge circuit showed distinct change in measured off-balance voltage with infused tea leaves of different kinds when compared with the response in plain boiling water. A typical response curve with two different kinds of tea leaves, CTC and Orthodox tea, are presented in Fig.4. The difference in response with tea as compared with pure water is quite substantial. This shows that the effect of VOC's on sensor response is quite high. The high response is due to porous nanostructure of $\mathrm{ZnO}$. The pore sizes of the nanostructured sensing element may be close to the organic molecules and so the adsorptions of these molecules are greatly intensified. This also imparts selectivity to some molecules. The molecules whose dimensions matches with that of the pores are adsorbed more resulting in higher response.

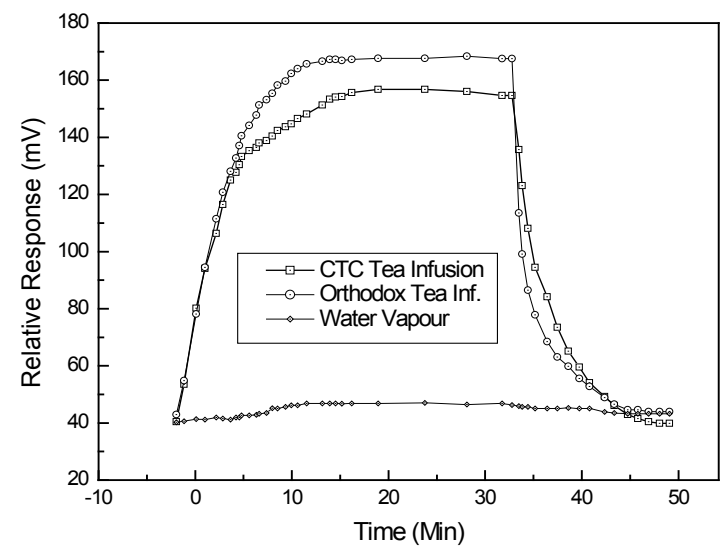

Fig.4: Response of the $\mathrm{ZnO}$ nanowire gas sensors measured at temperature $200^{\circ} \mathrm{C}$ with Orthodox tea and CTC tea infusion (at $100^{\circ} \mathrm{C}$ ) and compared with response in plain water vapour.

Results shows slightly lower concentration of VOC is detected for CTC compared to Orthodox tea which is in accordance to Tea tasters reports that indicates Orthodox tea has superior flavour characteristics. The difference may be due to the presence of less VOC's in CTC leaves.

\section{Variation of response sensitivity with operating temperature}

The sensor operating temperature is varied by controlling the heater current in the coil attached to the substrate. Results are presented in Fig. 5 for two kinds of two infusion. It shows that while the tea infusion temperature being the boiling point of water $\left(100^{\circ} \mathrm{C}\right)$, that maximum sensitivity is obtained at around 100$200^{\circ} \mathrm{C}$.

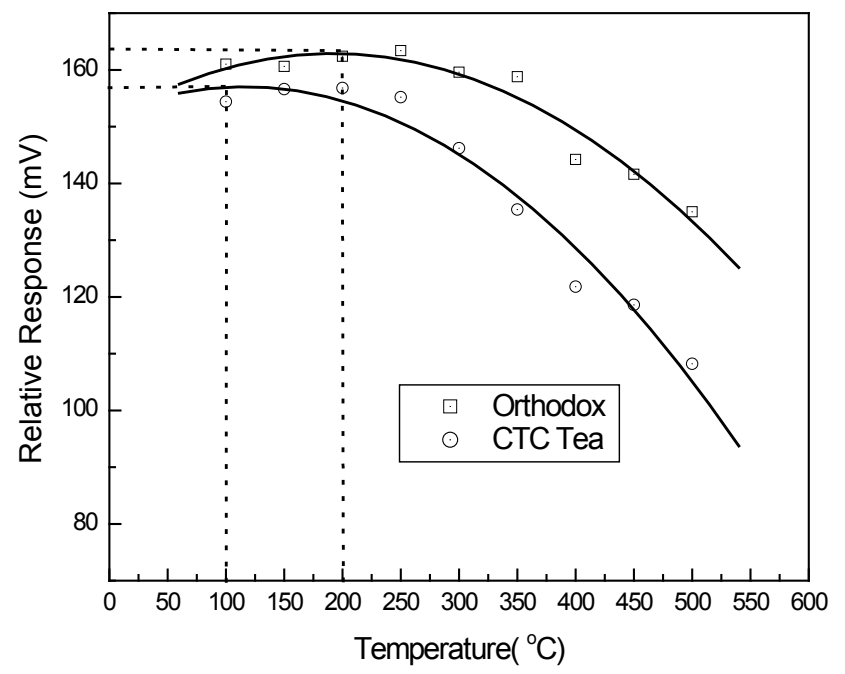

Fig.5: Response of the $\mathrm{ZnO}$ nanowire gas sensors are measured with Orthodox tea and CTC with varying temperature.

Lowering of sensitivity with higher temperature could be explained due to following fact that adsorbtion of VOC molecules over nano-porous sensor substrate is reduced at elevated temperatures. The little rise in response for the range $100^{\circ} \mathrm{C}$ to $200^{\circ} \mathrm{C}$ can be due to higher mobility of VOC components.

\section{Measurement of sensor characteristics}

The sensitivity, response time and signal-to-noise ratio of two kinds of tea infusion are presented in Table-I. The sensitivity of $\mathrm{ZnO}$ based nanosensor is defined as $\% \mathrm{~S}=\left(\mathrm{R}_{\mathrm{g}}-\mathrm{R}_{\mathrm{a}}\right) / \mathrm{R}_{\mathrm{a}}=\Delta \mathrm{R} / \mathrm{R}_{\mathrm{a}}$

where $R_{a}$ and $R_{g}$ are the resistance of the sensing film in the atmosphere to be measured and the atmosphere that are referenced, respectively. In our case percentage change in output voltage can give an indication of sensitivity of the sensing system. Response time is the time taken by the sensing element to reach $90 \%$ of the final stable value of the response while the Signal-tonoise ratio is measured by the signal response divided by the mean fluctuation of results from its average value. 
Table-I: Response characteristics of semiconducting $\mathrm{ZnO}$ film sensing devices when exposed with Darjeeling Orthodox tea and CTC tea.

\begin{tabular}{|c|c|c|c|}
\hline Type of tea & $\begin{array}{c}\text { Sensitivity } \\
(\%)\end{array}$ & $\begin{array}{c}\text { Response } \\
\text { time (Sec) }\end{array}$ & $\begin{array}{c}\text { Signal-to-Noise } \\
(\mathrm{S} / \mathrm{N}) \text { Ratio }\end{array}$ \\
\hline Orthodox & 0.12 & 540 & 127 \\
\hline CTC & 0.13 & 600 & 64 \\
\hline
\end{tabular}

It is observed that sensitivity of CTC tea is higher than that of Orthodox tea. However the orthodox tea has got faster response. The signal-to-noise ratio for Orthodox tea leaves has got higher value than that of CTC tea. The differences in sensitivity are due to different types of organic molecules vaporized for different types of tea leaves. The response time is related to the vapourization rate of organic molecules concerned. At same temperature, different organic molecules vaporize at different time. As the VOC compositions of different types of tea are different, the vaporization rates of VOC's are different, resulting in differences in response time.

\section{Conclusion}

Nanostructured sensing element of $\mathrm{ZnO}$ was fabricated on glass substrate. The microstructure shows neat columnar structure with uniform porosity. X-ray diffractogram shows formation of pure $\mathrm{ZnO}$ phase. The nanostructured $\mathrm{ZnO}$ film showed distinct change in their resistivity with infused tea leaves of different types. Due to its characteristic pore structure organic gas molecules are adsorbed over sensing surface resulting in selective response with different types of tea. Sensitivity of CTC tea is found to be lower than that of Orthodox tea which may be due to the more number of flavoury VOC's in Orthodox tea infusion. The response time and signal-to-noise ratio in Orthodox tea are also better than CTC tea. Further investigation is under progress to fine tune the response of the two types of tea leaves by changing the size of the microstructures and also by doping $\mathrm{ZnO}$ film with appropriate materials.

\section{Acknowledgements}

Authors are thankful to Department of Physics, North Bengal University, Siliguri, for providing laboratories facilities. One of the authors, I. B. Karki is thankful to UGC (Nepal), INSA (India) and NAST (Nepal) for

financial assistance for carrying out this work.

\section{References}

1 N. Bhattacharyya, R. Bandyopadhyay, M. Bhuyan, B. Tudu, D. Ghosh, and A. Jana, "Electronic nose for black tea classification and correlation of measurements with "Tea Taster" marks", IEEE Trans. Instrum. Meas., Vol. 57, No. 7, pp. 1313-1321, Jul. 2008.

2 R. Dutta, E. L. Hines, J. W. Gardner, K. R. Kashwan, and M. Bhuyan, "Tea quality prediction using a tin oxide-based electronic nose: An artificial intelligence approach", Sens. Actuators B, Vol. 94, pp. 228-237, Sep. 2003.

3 J. Spadavecchia, G. Ciccarella, R. Rella, S. Capone, P. Siciliano, Sensors Actuat. B-Chem 96 (2003) 489-497.

4 P. Semmelroch, W. Grosh, J. Agr. FoodChem. 44 (1996) 537543.

5 V. Kumar, S. Sen, K.P. Muthe, N.K. Gaur, S.K. Gupta, J.V. Yakhmi, Sens. Actuat. B, 138 (2009) 587-590.

6 B. Wacogne, M.P.Roe, T.A. Pattinson, Appl. Phys. Lett. 67 (1995) 1674.

7 A. Barker, S. Crowther, D. Rees Sens. Actuators A, 58(1997) 229.

8 M.H. Koch, P.Y. Timbrell, R.N. Lamb, Semicond Sci Technol 10 (1995) 1523.

9 K. Keis, E. Magnusson, H. Lindström, Sol Energy Mater Sol Cells, 73 (2002) 51.

10 L. Stolt, J. Hedström, J. Kessler, Appl. Phys. Lett. 62 (1993) 597.

11 Ü. Özgür, Ya. I. Alivov, C. Liu, A. Teke, M. A. Reshchikov, S. Doğan, V. Avrutin, S.-J. Cho, and H. Morkoç J. Appl. Phys. 98, 1-103,2005, A comprehensive review of $\mathrm{ZnO}$ materials and devices.

12 Y.Wu, H. Yan, M. Huang, B. Messer, J.H. Song, P. Yang, Eur. J. Chem. 8 (2002) 1260.

13 R. Konenkamp, R.C. Word, C. Schlegel, Appl, Phys, Lett., 85 (2004) 6004.

14 H. Tang, M. Yan, X. Ma, H. Zhang, M.Wang, D. Yang, Sens. Actuators, B, 113 (2006) 324.

15 W. Shen, Y. Zhao, C. Zhang, Thin Solid Films, 483 (2005) 382.

16 Q. Zhang, C. Xie, S. Zhang, A. Wang, B. Zhua, L. Wang and Z. Yang, Sensors Actuat. B, 110 (2005) 370-376.

17 N. Bhattacharyya, R. Bandyopadhyay, M. Bhuyan, B. Tudu, D. Ghosh, A. Jana, Electronic nose for black tea classification and correlation of measurements with "Tea Taster" marks, IEEE Trans. Instrum. Meas. 57 (2008) 1313-1321.

18 Bipan Tudu, Bikram Kow, Nabarun Bhattacharyya, Rajib Bandyopadhyay, Normalization techniques for gas sensor array as applied to classification for black tea, International Journal on Smart Sensing and Intelligent Systems, 2, 1 (2009)

19 A.S. Polo, N.Y. Iha, Sol. Energy Mater. Sol. Cells 90 (2006) 1936.

20 C.G. Garcia, A.S. Polo, N.Y. Iha, J. Photochem. Photobiol. A 160 (2003) 87. 